\section{The gender debate: science promises an honest investigation of the world}

SIR - Ben Barres's Commentary article

“Does gender matter?" (Nature 442, 133-136; 2006) misrepresents my position.

In my book The Blank Slate (Allen Lane, London, 2002), and in a published debate (www.edge.org/3rd_culture/debate05/ debate05_index.html), I reviewed a large empirical literature showing differences in mean and variance in the distributions of talents, temperaments and life priorities among men and women. Given these differences, some favouring men, some women, it is unlikely that the proportions of men and women in any profession would be identical, even without discrimination. That is probably one of several reasons that the sex ratio tips towards women in some scientific disciplines (such as my own, developmental psycholinguistics) and towards men in others. Barres renders this conclusion as "a whole group of people is innately wired to fail" - an egregious distortion.

Barres claims that I have denied that sex discrimination is a significant factor in professional life, whereas I have repeatedly stated the opposite, and indeed provided a jacket endorsement for Virginia Valian's book Why So Slow? (MIT Press, Cambridge, 1998) that summarized the evidence.

As for encouraging women in science: in my experience, students of both sexes are attracted to science because it promises an honest investigation into how the world works, an alternative to the subjectivity, simplistic dichotomies and moralistic namecalling that characterize politics and personal quarrels. Let's hope Barres's Commentary article does not discourage them.

\section{Steven Pinke}

Department of Psychology,

Harvard University, Cambridge,

Massachusetts 02138, USA

\section{Let's encourage gentler, more reflective scientists}

SIR - I am one of three men that Ben Barres, in his Commentary article ${ }^{1}$, pins up in a rogues' gallery and accuses of crimes against women. His article invents and then criticizes the 'Larry Summers Hypothesis', for which he cites three sources ${ }^{2-4}$. I urge readers to look at those sources and ask themselves whether Barres has misrepresented our arguments and views.

Specifically, Barres accuses me of arguing that women have "lesser innate abilities": this is not true, it is not what I wrote, it is not what I meant and it is not what I think. However, I do believe that there are significant differences in the psychological characteristics of populations of boys and girls as well as men and women (some differences favour females, some males) a truth that Barres makes use of.

For example, if (as Barres states), men are responsible for 25 times as many murders as women, does that statistic make women inferior? I think not.

Likewise, if more women than men tend to avoid the vicious struggle to survive in science, is this an argument that women are less well equipped? Not so. In a recent article ${ }^{4}$, I argue that scientists need to open their doors to gentler, more reflective women and men. And that if we do, we will encourage talented but less aggressive people, and the proportion of women at the top in science will rise as a welcome side effect.

Peter A. Lawrence

Division of Cell Biology,

Medical Research Council Laboratory

of Molecular Biology,

Hills Road, Cambridge CB2 2QH, UK

1. Barres, B. A. Nature 442, 133-136 (2006).

2. Summers, L. Letter to the Faculty Regarding NBER Remarks www.president.harvard.edu/speeches/summers/2005/ facletter.html (2005).

3. The Science of Gender and Science. Pinker vs. Spelke: A Debate www.edge.org/3rd_culture/debate05/debate05_index. html (2005)

4. Lawrence, P. A. PLoS Biol. 4, 13-15 (2006).

\section{Bias was built into research from the beginning}

SIR - As a basic scientist attempting to understand the mechanistic basis of sex differences in the brain, I found Ben Barres's Commentary article ${ }^{1}$ of particular interest.

The existence of robust and reliable sex differences in brain regions relevant to the control of reproduction cannot be refuted. However, my research group spent a year of frustration trying to apply the same principles to putative sex differences in cognition. This ended with the epiphany that even the standard laboratory rat shows few, if any, sex differences in the morphometry of regions relevant to cognition such as the hippocampus, and that the learning ability of both sexes is essentially the same ${ }^{2}$.

A search of the literature revealed that one of the first reports of sex differences or hormonal modulation of learning in rats, published in 1926, cites the 'fact' that such differences are reliably established in humans as supporting evidence (and note, the author was a woman $)^{3}$. Thus, even the fundamental science of learning in animal models was tainted by bias from its inception. Only with the influx of a large number of women scientists is the notion of superior male spatial ability beginning to be challenged.
Data are now being reinterpreted as showing a difference in learning strategy rather than ability ${ }^{4,5}$.

When I had the fortune to meet Ben Barres a few years ago, he told me his anecdote about losing the ability to cry easily after changing his gender to male, and suggested that sex differences in the lachrymal gland would be an excellent topic for study. At the time, I laughed at his naive notion that a behavioural sex difference would be the result of a peripheral gland. But now, I am not so sure.

Margaret M. McCarthy

Departments of Physiology and Psychiatry, University of Maryland Baltimore School of Medicine, 655 W. Baltimore Street,

Baltimore Maryland 21201, USA

1. Barres, B. A. Nature 442, 133-136 (2006)

2. McCarthy, M. M. \& Konkle, A. T. M. Front. Neuroendocrin. 26, 85-102 (2005).

3. Ball, J. Am. J. Physiol. 78, 533-536 (1926).

4. Perrot-Sinal, T. S., Heale, V. R., Ossenkopp, K. P. \& Kavaliers, M. Behav. Neurosci. 110, 1309-1320 (1996).

5. Beiko, J., Lander, R., Hampson, E., Boon, F. \& Cain, D. P. Behav. Brain Res. 151, 239-253 (2004).

\section{Holding the centre among the scatter-brained}

SIR - In his Commentary article "Does gender matter?" (Nature 442, 133-136; 2006), Ben Barres counters suggestions that women are underrepresented in the sciences because of innate ability.

Barres's graph of maths scores for boys and girls aged 4 to 18 shows that the differences in abilities are small. And yet most winners of the US Putnam mathematics competition each year are men. Putnam winners clearly fall on the far-right tail of the maths IQ curve, and it's precisely in the tails that the gender differences become clear. Male aptitude is more variable and, as Marilyn vos Savant points out in her excellent column "Are men smarter?" (www.parade.com/articles/ editions/2005/edition_07-17-2005/ featured_0), men are overrepresented at both ends of the spectrum. (I call them 'scatter-brained'.)

Although I wouldn't hesitate to speak out in the face of blatant discrimination, as Barres urges, my advice differs from his. Grow a thick skin. If you encounter bias, choose your battles. Don't get distracted by the small stuff, but speak up when it really matters.

Donna L. Dierker

Department of Anatomy \& Neurobiology, Washington University School of Medicine, 660 South Euclid Avenue, St Louis,

Missouri 63110, USA

Readers are encouraged to add their comments to the Ben Barres Commentary on the Nature News Blog at: http://blogs.nature.com/news/blog/ 2006/07/does_gender_matter.html 